Article

\title{
Reactively Sputtered Sb-GaN Films and its Hetero-Junction Diode: The Exploration of the $n$-to- $p$ Transition
}

\author{
Cao Phuong Thao ${ }^{1}$, Thi Tran Anh Tuan ${ }^{2, *}$, Dong-Hau Kuo ${ }^{3, *(1)}$, Wen-Cheng Ke ${ }^{3}$ and \\ Thach Thi Via Sa Na ${ }^{1}$ \\ 1 School of Engineering and Technology, Tra Vinh University, Tra Vinh 87000, VietNam; \\ cpthao@tvu.edu.vn (C.P.T.); viasana@tvu.edu.vn (T.T.V.S.N.) \\ 2 School of Basic Sciences, Tra Vinh University, Tra Vinh 87000, VietNam \\ 3 Department of Materials Science and Engineering, National Taiwan University of Science and Technology, \\ Taipei 10607, Taiwan; wcke@mail.ntust.edu.tw \\ * Correspondence: thitrananhtuan@tvu.edu.vn (T.T.A.T.); dhkuo@mail.ntust.edu.tw (D.-H.K.); \\ Tel.: +886-2-27303291 (D.-H.K)
}

Received: 11 February 2020; Accepted: 25 February 2020; Published: 27 February 2020

\begin{abstract}
Sb anion-substituted gallium nitride films were fabricated by radio frequency reactive sputtering with single Sb-containing cermet targets with different $\mathrm{Sb}$ contents under $\mathrm{Ar} / \mathrm{N}_{2}$ atmosphere. n-type GaN films with electron concentration of $(1.40 \pm 0.1) \times 10^{17} \mathrm{~cm}^{-3}$ inverted to p-type Sb-GaN with hole concentration of $(5.50 \pm 0.3) \times 10^{17} \mathrm{~cm}^{-3}$. The bandgap energy of Sb anion-added Sb-GaN films decreased from 3.20 to $2.72 \mathrm{eV}$ with increasing $\mathrm{Sb}$ concentration. The formation of p-type $\mathrm{Sb}-\mathrm{GaN}$ is attributed to the formation of $\mathrm{Ga}$ vacancy at higher $\mathrm{Sb}$ concentration. The coexistence of $\mathrm{Sb}$ at the Ga cation site and $\mathrm{N}$ anion site is an interesting and important result, as GaNSb had been well developed for highly mismatched alloys. The hetero-junction with p-type Sb-GaN/n-Si diodes was all formed by radio frequency (RF) reactive sputtering technology. The electrical characteristics of $\mathrm{Sb}-\mathrm{GaN}$ diode devices were investigated from -20 to $20 \mathrm{~V}$ at room temperature (RT).
\end{abstract}

Keywords: Sb acceptor; GaN; RF sputtering; thin film; hole concentration

\section{Introduction}

Gallium nitride $(\mathrm{GaN})$ is a versatile semiconductors material with wide direct band gap, good thermal conductivity, high breakdown voltage, and high electron mobility [1]. GaN and its alloys have been employed for light-emitting diodes and laser diodes [2,3], field effect transistors, and hetero-junction bipolar transistors [4,5]. GaN films have been grown by many fabrication methods, including metal-organic chemical vapor deposition (MOCVD), metal-organic vapor phase epitaxy (MOVPE), and molecular beam epitaxy (MBE) [6-8].

To further develop the electronic and optoelectronic properties, it is advantageous to control the growth of GaN film so that it is $p$-type hole conduction by controlling acceptor concentration. In 1989, H. Amano et al. studied Mg-doped GaN films by low-energy electron beam irradiation (LEEBI) treatment and their films converted into a $p$-type semiconductor with low resistivity of $35 \Omega \cdot \mathrm{cm}$, hole concentration of $2 \times 10^{16} \mathrm{~cm}^{-3}$, and electrical mobility of $8 \mathrm{~cm}^{2} \cdot \mathrm{V}^{-1} \cdot \mathrm{s}^{-1}$ [9]. In $1991, \mathrm{~S}$. Nakamura developed a two-flow (TF) MOCVD to grow GaN with significantly improved crystallinity, uniformity, and electrical properties [10]. In 1992, S. Nakamura et al. achieved low resistivity p-type GaN film grown by TF-MOCVD at temperature above $700{ }^{\circ} \mathrm{C}$ under a $\mathrm{N}_{2}$ atmosphere. The resistivity of the Mg-GaN film remarkably decreased to $2 \Omega \cdot \mathrm{cm}$, with a hole concentration of $3 \times 10^{17} \mathrm{~cm}^{-3}$ and electrical mobility of $10 \mathrm{~cm}^{2} \cdot \mathrm{V}^{-1} \cdot \mathrm{s}^{-1}$ [11]. In 1998, C.G. Van de Walle showed that there was a limit in the hole 
concentration of $p$-type GaN due to the solubility of Mg in GaN [12]. In 2010, C. Guarneros et al. had successfully grown GaN and Mg-GaN films on sapphire substrates with MOCVD, and investigated the optical and electrical properties of $n-\mathrm{GaN}$ and $p-\mathrm{GaN}$ films [13]. They enhanced the electrical characteristics of $p-\mathrm{MgGaN}$ films by annealing, resulting in a higher hole concentration of $4.82 \times$ $10^{19} \mathrm{~cm}^{-3}$, lower resistivity of $7 \times 10^{-3} \Omega \cdot \mathrm{cm}$, and higher mobility of $18.4 \mathrm{~cm}^{2} \cdot \mathrm{V}^{-1} \cdot \mathrm{s}^{-1}$. In 1995 , S. Fischer group studied $\mathrm{Zn}$ dopant as acceptors in $\mathrm{GaN}$ and reported the blue light-emitting characteristic of $\mathrm{Zn}$-doped GaN. After being compared with Mg-doped GaN, Zn-GaN showed higher activation energy. [14]. In 1988, H. Amano et al. used the MOVPE method to deposit a $~ 50 \mathrm{~nm}$ AlN buffer layer on $a$ - and $c$-axis sapphire substrates at $950{ }^{\circ} \mathrm{C}$, following the deposition of $0.3 \mu \mathrm{m}$-thick $\mathrm{Zn}$-GaN film with trimethylgallium (TMG), ammonia $\left(\mathrm{NH}_{3}\right)$, and Ethyl zinc (DEZ) as the sources of $\mathrm{Ga}, \mathrm{N}$, and $\mathrm{Zn}$, respectively. The $\mathrm{Zn}-\mathrm{GaN}$ film had good quality with no presence of cracks [15]. In 2014, our group successfully deposited Mg-doped GaN films on Si (100) substrates at and below $400{ }^{\circ} \mathrm{C}$ by radio frequency reactive sputtering technology. At $10.2 \% \mathrm{Mg}, \mathrm{Mg}-\mathrm{GaN}$ converted into a p-type semiconductor with hole concentration of $9.37 \times 10^{16} \mathrm{~cm}^{-3}$, high electrical mobility of $345 \mathrm{~cm}^{2} \cdot \mathrm{V}^{-1} \cdot \mathrm{s}^{-1}$, and high conductivity of $3.23 \mathrm{~S} \cdot \mathrm{cm}^{-1}$ [16].

Many reports have recently detailed the structural, optical, and electrical behaviors of GaN-Sb alloys grown as highly mismatched alloys (HMAs). However, the synthesis of HMAs is difficult due to the large size/electronegativity mismatch between anions of $\mathrm{N}$ and $\mathrm{Sb}$, and unconventionally low growth temperature to be utilized for $\mathrm{Sb}$ incorporation. The most common growth method for $\mathrm{GaN}_{1-x} \mathrm{Sb}_{x}$ has been molecular beam epitaxy. Segercrantz el al. reported the optical characteristics of $\mathrm{GaN}_{1-x} \mathrm{Sb}_{x}$ films formed with $\mathrm{Sb}$ shutter to have $\mathrm{Sb}$ content of $x$ at $0.03-0.42 . \mathrm{GaN}_{1-x} \mathrm{Sb}_{x}$ films with Sb compositions less than $20 \%$ are of interest for photo-electrochemical (PEC) applications [17]. In 2016, N. Segercrantz further presented the influences of rapid thermal annealing on the structural and electronic properties of $\mathrm{GaN}_{1-x} \mathrm{Sb}_{x}$ films with $x \geq 0.06$ grown by MBE at low temperature. P-type $\mathrm{GaN}_{1-x} \mathrm{Sb}_{x}$ semiconductor films were measured to have higher hole concentrations of $\sim 10^{19} \mathrm{~cm}^{-3}$ after annealing at $400{ }^{\circ} \mathrm{C}$ [18]. K. M. Yu also studied $\mathrm{GaN}_{1-x} \mathrm{Sb}_{x}$ grown on sapphire substrate by MBE at low temperature. They found that the growth temperature affected the $\mathrm{Sb}$ incorporation and the resulting structural and optical properties of $\mathrm{GaN}_{1-x} \mathrm{Sb}_{x}$ films [19]. By using the low temperature MBE for the deposition of GaN-Sb films, K. M. Yu further investigated the structural and optical properties of N-rich $\mathrm{GaN}_{1-x} \mathrm{Sb}_{x}$ thin films [20]. These N-rich $\mathrm{GaN}_{1-x} \mathrm{Sb}_{x}$ films with less than 5 at.\% $\mathrm{Sb}$ had a bandgap of $\sim 2 \mathrm{eV}$, which is suitable for PEC application. By using both positron annihilation measurement and ab initio calculation, N. Segercrantz discussed the possible reasons for the enhanced conductivity of the $p$-type $\mathrm{GaN}_{x} \mathrm{Sb}_{1-x}$ films grown by plasma-assisted MBE [21]. The $\mathrm{GaN}_{x} \mathrm{Sb}_{1-x}$ film is interesting and has demonstrated special properties, but all the GaNSb made by MBE had the Sb incorporated at the $\mathrm{N}$ anion site to behave as $\mathrm{Sb}^{3-}$. In 2016, K. M. Yu studied and reported the composition range, the electronic band, and optical properties of highly mismatched $\mathrm{GaN}_{1-x} \mathrm{Sb}_{x}$ alloys [22].

At present, there are few studies for the deposition of $\mathrm{Sb}$-added $\mathrm{GaN}$ thin films by reactive radio frequency (RF) sputtering technology, which has beneficial characteristics such as relative low-cost, easy cleaning, low working temperature, and safety in the working environment. By using single ceramic target made with multiple components to get rid of troubles in utilizing liquid Ga target, our group has effectively used radio frequency reactive sputtering technology for III-nitride alloys. Due to the composition design of targets over a wide range, the different doping studies in GaN and its alloys have been quite successfully demonstrated [23-26]. With a systematic modification in the film composition, the effect of the Sb dopant on the solid solubility, the topology, and properties of $\mathrm{Sb}-\mathrm{GaN}$ films can be studied and understood for the sake of its development on the emerging field. For scientific interests, Sb-doped GaN thin films with different $\mathrm{Sb}$ contents on $\mathrm{Si}$ (100) wafer are deposited by RF reactive sputtering technology with single cermet antimony-containing targets in this work. The properties of Sb- $x$-GaN films and the performance of fabricated diode device on $n$-Si are investigated. 


\section{Experimental Details}

The deposition of Sb-x-GaN films on both $\mathrm{SiO}_{2} / \mathrm{n}$-type $\mathrm{Si}$ (100) and n-type $\mathrm{Si}$ (100) substrates, with electrical resistivity of $\sim 1-10 \Omega \cdot \mathrm{cm}$, electron concentration of $\sim 10^{15} \cdot \mathrm{cm}^{-3}$, diameter of 2 inches, thickness of $\sim 550 \mu \mathrm{m}$ and electrical mobility of $\sim 200 \mathrm{~cm}^{2} \cdot \mathrm{V}^{-1} \cdot \mathrm{s}^{-1}$, was grown by radio frequency reactive sputtering with single cermet targets of various $\mathrm{Sb}$ dopants. Five $\mathrm{Sb}-x$-GaN targets with $x$ of the $\mathrm{Sb} /(\mathrm{Sb}+\mathrm{Ga})$ molar ratios at $0,0.04,0.07,0.14$, and 0.2 were used for the deposition and labeled as $\mathrm{Sb}-x$-GaN film with $x=0,0.04,0.07,0.14$, and 0.2. The SbGaN cermet targets consisting of different $\mathrm{Sb}$ contents were formed by hot-pressing the mixing powders of $\mathrm{GaN}$ ceramic and metallic $\mathrm{Sb}$ and $\mathrm{Ga}$ in accordance with composition design. To remove the oxygen and impurities present in deposition chamber, mechanical and diffusion pumps had been applied to vent the chamber to pressure lower than $1 \times 10^{-6}$ torr before sputtering. As the influences of RF sputtering power and heating temperature on properties of doped GaN films had been well studied in our previous works, the RF sputtering power and substrate temperature in this work were set in $120 \mathrm{~W}$ and $300{ }^{\circ} \mathrm{C}$, respectively, with the deposition pressure kept at $9 \times 10^{-3}$ torr for 30 min and the mixing $\left(\mathrm{Ar}+\mathrm{N}_{2}\right)$ gas flow rates at $5 \mathrm{sccm}$ and $15 \mathrm{sccm}$, respectively. A larger amount of $\mathrm{N}_{2}$ gas rate was used in the deposition to avoid nitrogen deficiency in GaN. The size of the single cermet target employed in RF sputtering was $5.08 \mathrm{~cm}$ ( 2 inches) and the work distance between $\mathrm{Sb}$-containing target and substrates in the deposition chamber was kept at $5 \mathrm{~cm}$.

By employing RF reactive sputtering technology, the hetero-junction diodes have been also fabricated by depositing $\mathrm{Sb}-x$-GaN thin films on $n$-Si (100) wafers. The diode structure was in the top-top electrode mode formed by sputtering the p-SbGaN film on n-Si substrate shown in Figure 1a. As known in the modeling of MOS, MS, homo or hetero junction diode, and metals with high work-function ( $\mathrm{Pt}, \mathrm{Mo}, \mathrm{Ni}, \ldots$ ) were often used to make Schottky contact with $n$-type semiconductor and Ohmic contact with $p$-type semiconductor. On the other hand, metals with low work-function $(\mathrm{Al}, \mathrm{Ag}, \ldots)$ were often used to make ohmic contact with n-type semiconductor and Schottky contact with p-type semiconductor. Modeling of $\mathrm{Pt} / p-\mathrm{Sb}-\mathrm{GaN} / n-\mathrm{Si} / \mathrm{Al}$ in this work used Al to form ohmic contact with $n$-Si and $\mathrm{Pt}$ to form Ohmic contact with $p$-Sb-GaN. Figure $1 \mathrm{~b}, \mathrm{c}$ presented the I-V characteristics of $\mathrm{Al} / n-\mathrm{Si}(100) / \mathrm{Al}$ and $\mathrm{Pt} / p-\mathrm{SbGaN} / \mathrm{Pt}$ Ohmic contacts, respectively. The diodes with hetero-junction were fabricated by depositing the $p$-type $\mathrm{Sb}-0.07-\mathrm{GaN}, \mathrm{Sb}-0.14-\mathrm{GaN}$, and $\mathrm{Sb}-0.2-\mathrm{GaN}$ films on $n$-Si substrates. The commercial $\mathrm{Al}$ and $\mathrm{Pt}$ targets $\left(99.999 \%\right.$ ) were used to deposit the electrodes at $200{ }^{\circ} \mathrm{C}$ for $30 \mathrm{~min}$ on the top of film. The physical processes for fabricating the diodes with our deposited III-nitride thin films were detailed in our previous works [16,25,27-29].

X-ray photoelectron spectroscopy (XPS) measurements of films were obtained with VG scientific ESCALAB 250 (Billerica, MA, USA) spectrometer under Al K $\alpha$ X-rays (hv $=1486.6 \mathrm{eV}$ ) radiation. The results were calibrated with carbon $(\mathrm{C} 1 \mathrm{~s})$ binding energy. X-ray diffractometry (XRD, D8 Discover, Bruker, Billerica, MA, USA) and high-resolution transmission electron microscopy (HRTEM, Technai G2, Philips, WI, USA) were used to investigate the structural properties of the of Sb- $x$-GaN films. Atomic force microscopy (AFM, Dimension Icon, Bruker, Billerica, MA, USA) was used to assess the surface properties. The surface morphology, cross-sections, and EDS compositional data of Sb-x-GaN films were studied by scanning electron microscopy (SEM, JSM-6500F, JEOL, Tokyo, Japan) with energy dispersive spectrometry (EDS, JSM-6500F, JEOL, Tokyo, Japan). The absorption spectra for Sb-doped GaN thin films were obtained by ultraviolet-visible (UV-vis) spectrometry (V-670, Jasco, Tokyo, Japan). The electrical properties were investigated by Hall measurements (HMS-2000, Ecopia, Tokyo, Japan) with a maximum magnetic field of $0.51 \mathrm{~T}$. The values of EDS composition analyses, the film thickness, surface roughness, electrical mobility, concentration and conductivity of the Sb-x-GaN samples were measured and calculated with the standard deviation (SD) at 5\%. The electrical behaviors of the diodes were examined with I-V curves obtained with a Semiconductor Device Analyzer (Agilent, B1500A, Santa Crala, CA, USA) at RT. 
Electrode

$(300 \mathrm{~nm})$

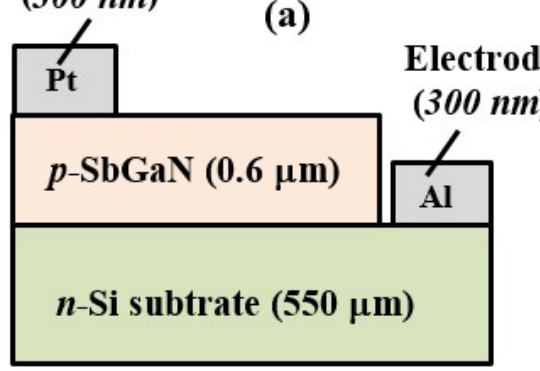

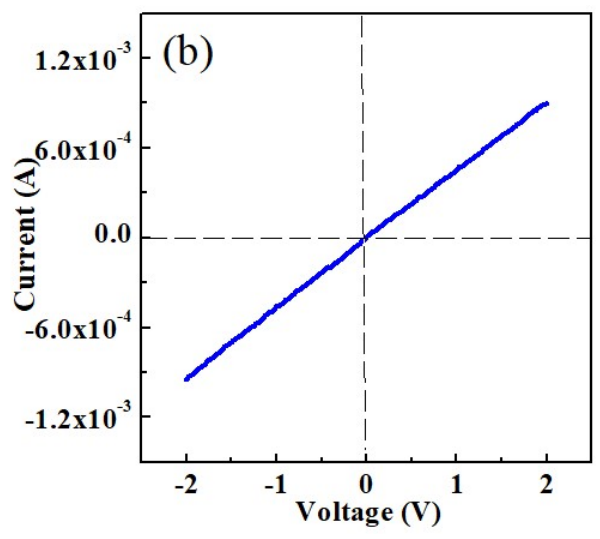

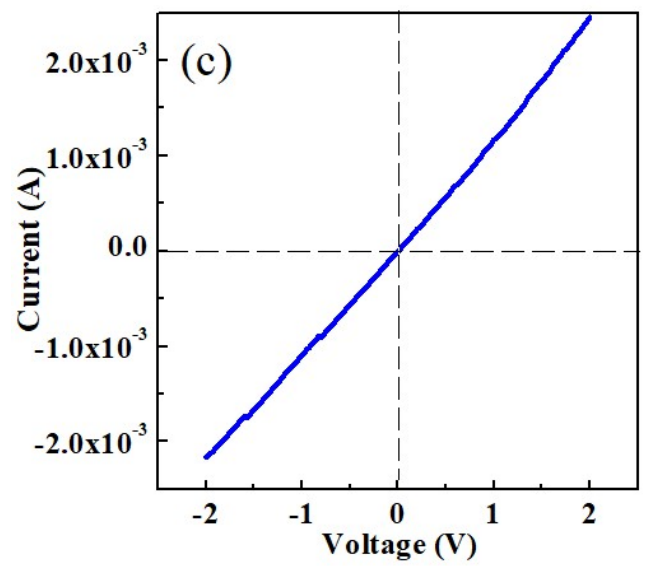

Figure 1. (a) The 2D layer structure of the $\mathrm{Sb}-x-\mathrm{GaN} / \mathrm{n}-\mathrm{Si}$ heterojunction diode. The I-V properties of (b) $\mathrm{Pt} / \mathrm{p}-\mathrm{SbGaN} / \mathrm{Pt}$ and (c) $\mathrm{Al} / \mathrm{n}-\mathrm{Si} / \mathrm{Al}$ Ohmic contacts.

\section{Results and Discussion}

Figure 2 shows (a) XPS survey scan and high resolution, (b) Ga 2p, (c) Sb 3d, and (d) N 1s spectra of the Sb-0.14-GaN film. XPS was used to determine the chemical surface properties of the Sb-0.14-GaN film deposited on $n$-Si (100) wafer doped with phosphorus. The XPS survey data and the XPS peaks of $\mathrm{Ga}, \mathrm{Sb}$, and $\mathrm{N}$ elements shown in Figure 1 were investigated with the low intensity peak of $\mathrm{C} 1 \mathrm{~s}$ at $284.6 \mathrm{eV}$ in binding energy as a reference. Figure $2 \mathrm{~b}$ shows the high resolution XPS spectrum with strong Ga 2p1/2 and Ga 2p3/2 peaks at $1145.7 \mathrm{eV}$ and $1118.81 \mathrm{eV}$, respectively, for the confirmation of $\mathrm{Ga}-\mathrm{N}$ bond in $\mathrm{GaN}$ [30]. The small peak at $1117.8 \mathrm{eV}$ was contributed to the $\mathrm{Ga}-\mathrm{O}$ bonding. Figure 2c shows the high resolution XPS peaks of $\mathrm{Sb} 3 \mathrm{~d} 3 / 2$ and $\mathrm{Sb} 3 \mathrm{~d} 5 / 2$ located at $540.2 \mathrm{eV}$ and $530.98 \mathrm{eV}$, respectively, for $\mathrm{Sb}^{3+}$ in $\mathrm{SbN}$ bond [31], while peaks at $358.4 \mathrm{eV}$ and $529.15 \mathrm{eV}$ in binding energy were determined for $\mathrm{Sb}^{3-}$ in $\mathrm{GaSb}$ bond [32,33].

From the areal analysis of XPS fitting peak for Sb-0.14-GaN film, the ratio of $\mathrm{Sb}^{3+}$ in $\mathrm{Sb}-\mathrm{N}$ was $73.3 \%$ and the ratio of $\mathrm{Sb}^{3-}$ in $\mathrm{Sb}-\mathrm{Ga}$ was $26.7 \%$. The $\mathrm{Sb}$ substitution in $\mathrm{GaN}$ has $\mathrm{Sb}$ mainly to the cation site of $\mathrm{Ga}$ and some to the anion site of $\mathrm{N}$. It can be the first observation to simultaneously show $\mathrm{Sb}$ in the valency states of $3+$ and 3-. In the $\mathrm{Sb} 3 \mathrm{~d} 5 / 2$ peak, there is the $\mathrm{O} 1$ s peak overlapping at $532.20 \mathrm{eV}$. The oxygen can come from the contamination and adsorption. Figure $2 \mathrm{~d}$ shows the high resolution XPS peak of N 1s peak, which includes the strongest peak at $397.15 \mathrm{eV}$ from the contribution of N-Ga bonding and two small peaks at $398.1 \mathrm{eV}$ from the N-Sb bond and $394.25 \mathrm{eV}$ from Ga auger peak [31].

Table 1 exhibits EDS analysis of the Sb- $x$-GaN films deposited on $\mathrm{Si}(100)$ substrate at the power of $120 \mathrm{~W}$ and depositing temperature of $300^{\circ} \mathrm{C}$ under the $\left(\mathrm{Ar}+\mathrm{N}_{2}\right)$ atmosphere with $\mathrm{Sb}_{\mathrm{x}} \mathrm{GaN}$ target at $x$ $=0,0.04,0.07,0.14$, and 0.20 . The Ga, Sb, and N percentages were listed in Table 1. Due to the XPS data for Sb-x-GaN, Sb exists at two valency states of 3+ and 3-. However, Sb-0.04-GaN and Sb-0.07-GaN with the low $\mathrm{Sb}$ contents and the high $\mathrm{Ga}$ contents above 50\% are not expected to have $\mathrm{Sb}$ to the $\mathrm{Ga}$ 
site. For Sb-0.2-GaN, it also had a low Ga content, so its Sb state is assumed to follow the behavior of $\mathrm{Sb}-0.14-\mathrm{GaN}$. With the consideration of site occupation, the cation/anion ratios were 1.02, 1.02, 0.99, 0.98 , and 0.96 for $\mathrm{Sb}-x-\mathrm{GaN}$ at $x=0,4,7,14$, and 0.2 . It can be concluded that there was an anion deficiency at a lower $\mathrm{Sb}$ content and a cation deficiency at a higher $\mathrm{Sb}$ content. The changes of $\mathrm{Sb}$ content in film composition were expected to modify film properties.
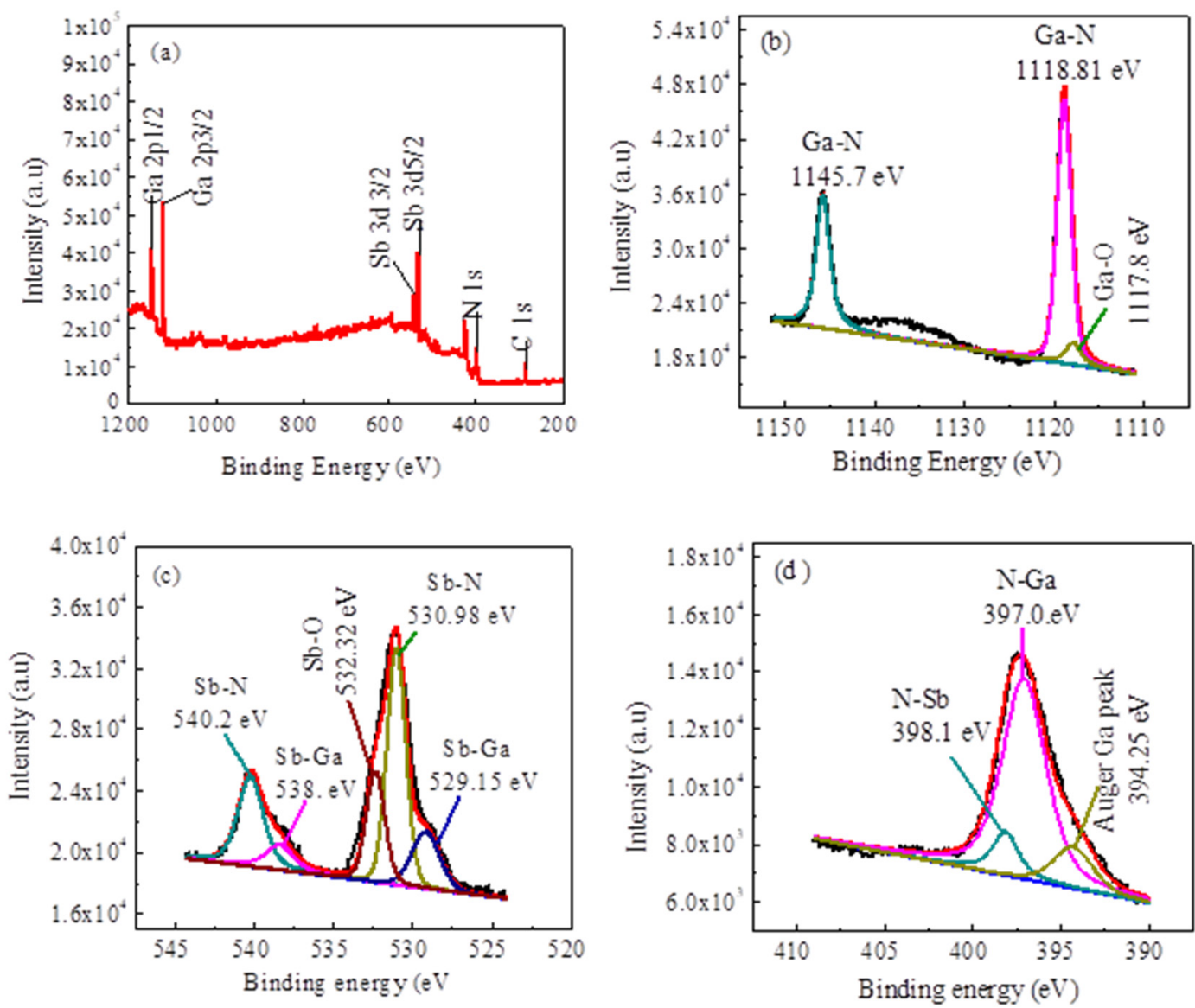

Figure 2. (a) XPS survey scan and high resolution, (b) Ga, (c) Sb, and (d) N spectra of Sb-0.14-GaN film.

Table 1. EDS composition analyses of Sb- $x$-GaN films at $x=0,0.04,0.07,0.14$, and 0.2.

\begin{tabular}{|c|c|c|c|c|c|c|}
\hline \multirow[t]{2}{*}{$x$} & \multirow{2}{*}{ Ga (at.\%) } & \multirow{2}{*}{$\mathrm{Sb}$ (at.\%) } & \multirow{2}{*}{ N (at.\%) } & \multicolumn{2}{|c|}{$\mathrm{Sb}$} & \multirow{2}{*}{ Cation/Anion } \\
\hline & & & & $\mathrm{Sb}^{3+}$ & $\mathrm{Sb}^{3-}$ & \\
\hline 0 & $50.56 \pm 2.53$ & - & $49.44 \pm 1.98$ & - & - & 1.02 \\
\hline 0.04 & $49.78 \pm 2.49$ & $0.80 \pm 0.04$ & $49.42 \pm 1.98$ & $\begin{array}{c}0 \\
(0 \%)\end{array}$ & $\begin{array}{c}0.80 \\
(100 \%)\end{array}$ & 0.99 \\
\hline 0.07 & $50.3 \pm 2.51$ & $1.45 \pm 0.08$ & $48.25 \pm 1.93$ & $\begin{array}{c}0 \\
(0 \%)\end{array}$ & $\begin{array}{c}1.45 \\
(100 \%)\end{array}$ & 1.01 \\
\hline 0.14 & $45.89 \pm 2.31$ & $4.92 \pm 0.25$ & $49.19 \pm 1.97$ & $\begin{array}{c}3.69 \\
(75 \%)\end{array}$ & $\begin{array}{c}1.23 \\
(25 \%)\end{array}$ & 0.98 \\
\hline 0.2 & $44.12 \pm 2.21$ & $6.49 \pm 0.33$ & $49.39 \pm 1.98$ & $\begin{array}{c}4.87 \\
(75 \%)\end{array}$ & $\begin{array}{c}1.62 \\
(25 \%)\end{array}$ & 0.96 \\
\hline
\end{tabular}

XRD patterns of the deposited Sb- $x$-GaN films with different $\mathrm{Sb}$ precursor ratios of $0,0.04$, $0.07,0.14$, and 0.2 are presented in Figure 3. Using the standard diffraction GaN data in PDF card No.76-0703, all sputtered Sb- $x$-GaN films had the same structure of hexagonal wurtzite. The films were polycrystalline with the distinct diffractions from the $(10 \overline{1} 0),(10 \overline{1} 1)$, and $(11 \overline{2} 0)$ planes. The films 
had a preferential $(10 \overline{1} 0)$ plane of growth and no second phases. The diffraction intensity of $(10 \overline{1} 0)$ peak decreased due to the increase of $\mathrm{Sb}$ dopant concentration in the deposited films. Table 2 lists all the investigated data from X-ray diffraction inspections. The (1010) peak slightly shifted from $32.44^{\circ}$ for Sb-0-GaN to $32.15^{\circ}$ for Sb-0.2-GaN. It displayed that lattice constant of $a$ and $c$, and the unit cell volume of Sb- $x$-GaN films increased as there was an increment of Sb dopant content in the $\mathrm{Sb}-x-\mathrm{GaN}$ films. The lattice constant of $c$ was $5.09 \AA$ for Sb-0-GaN and increased to 5.20, 5.21, 5.22, and $5.23 \AA$ for $\mathrm{Sb}-x$-GaN with $x=0.04,0.07,0.14$, and 0.20, respectively. Besides, $a$ was $3.13 \AA$ for Sb-0-GaN and increased to $3.19,3.20,3.21$, and $3.22 \AA$ for $\mathrm{Sb}-x$-GaN with $x=0.04,0.07,0.14$, and 0.20 , respectively. Unit cell volumes increased with the increase in the $\mathrm{Sb}$ content of $\mathrm{Sb}-x-\mathrm{GaN}$ films, which were 43.18, $45.83,46.26,46.60$, and $46.93 \AA^{3}$ at $x=0,0.04,0.07,0.14$, and 0.2 , respectively. From the $2 \theta$ value shown in Table 2, the full width at half maxima (FWHM) values of the (1010) peak possessed a slight increase from $0.31^{\circ}$ for $\mathrm{Sb}-0-\mathrm{GaN}$ and $0.32^{\circ}$ for Sb-0.04-GaN to $0.35^{\circ}, 0.42^{\circ}$, and $0.49^{\circ}$ for $\mathrm{Sb}-x-\mathrm{GaN}$ at $x=0.07$, 0.14 , and 0.2 , respectively. Besides, the FWHM value of the (1010) peak was a function of crystallite size. The crystallite sizes of films calculated with the Scherer equation were 29.7, 28.7, 26.3, 21.9, and $18.8 \mathrm{~nm}$ for the Sb- $x$-GaN films at $x=0,0.04,0.07,0.14$, and 0.20 , respectively. There was a reduction in the crystallite sizes of $\mathrm{Sb}-x$-GaN from 29.7 to $18.8 \mathrm{~nm}$ with increasing the $\mathrm{Sb}$ content.

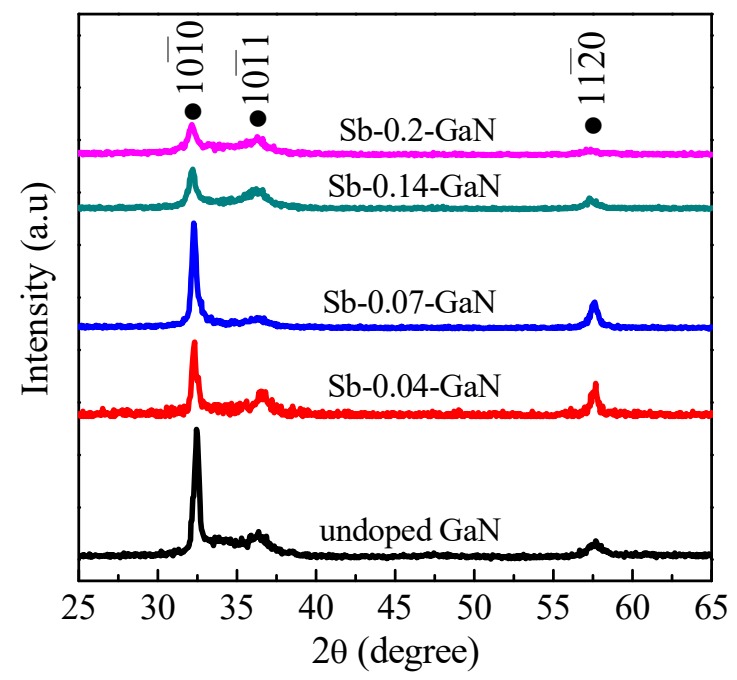

Figure 3. $\mathrm{XRD}$ patterns of $\mathrm{Sb}-x-\mathrm{GaN}$ films sputtered at temperature of $300{ }^{\circ} \mathrm{C}$ and radio frequency (RF) sputtering power of $120 \mathrm{~W}$ in $\mathrm{Ar} / \mathrm{N}_{2}$ atmosphere with different $\mathrm{Sb}$ contents $(x=0,0.04 .0 .07,0.14$, and 0.2 ) in single ceramic targets.

Table 2. Structural properties of the as-deposited Sb- $x$-GaN films $(x=0,0.04,0.07,0.14$, and 0.2$)$ obtained from the X-ray diffraction investigation.

\begin{tabular}{|c|c|c|c|c|c|c|}
\hline$x$ & $\begin{array}{c}2 \theta \\
(10 \overline{10}) \text { Peak }\end{array}$ & $a(\AA)$ & $c(\AA)$ & Volume $\left(\AA^{3}\right)$ & $\begin{array}{c}\text { FWHM (10̄̄o) } \\
\text { (degree) }\end{array}$ & $\begin{array}{l}\text { Crystallite } \\
\text { Size (nm) }\end{array}$ \\
\hline 0 & 32.44 & 3.13 & 5.09 & 43.18 & 0.31 & 29.7 \\
\hline 0.04 & 32.30 & 3.19 & 5.20 & 45.83 & 0.32 & 28.7 \\
\hline 0.07 & 32.25 & 3.20 & 5.21 & 46.26 & 0.35 & 26.3 \\
\hline 0.14 & 32.20 & 3.21 & 5.22 & 46.60 & 0.42 & 21.9 \\
\hline 0.2 & 32.15 & 3.22 & 5.23 & 46.93 & 0.49 & 18.8 \\
\hline
\end{tabular}

Figure 4 presents the surface morphology of Sb- $x$-GaN films with individual cross-section SEM patterns in the insets. The surface SEM images displayed that the deposited Sb-GaN films had surface smoothness and microstructure with their grain size in a nanosized scale. From the vertical cross-section SEM patterns in the insets of Figure 4, the thickness of Sb- $x$-GaN films increased from $(0.96 \pm 0.05)$ $\mu \mathrm{m}$ for $\mathrm{Sb}-0-\mathrm{GaN}$ to $(1.20 \pm 0.06) \mu \mathrm{m}$ for $\mathrm{Sb}-0.2-\mathrm{GaN}$. These films adhered well on substrate without cracks and voids. As shown in Table 3, the deposition rates of Sb- $x$-GaN films at $x=0,0.04,0.07,0.14$, 
and 0.2 were calculated to be $(32.0 \pm 1.6),(33.3 \pm 1.6),(38.0 \pm 1.9),(39.0 \pm 2.0)$, and $(40.0 \pm 2.0) \mathrm{nm} / \mathrm{min}$, respectively. There was a slight increment of the growth rate for the thicker film at higher Sb dopant content. It indicates that $\mathrm{Sb}$ accelerates the film growth.
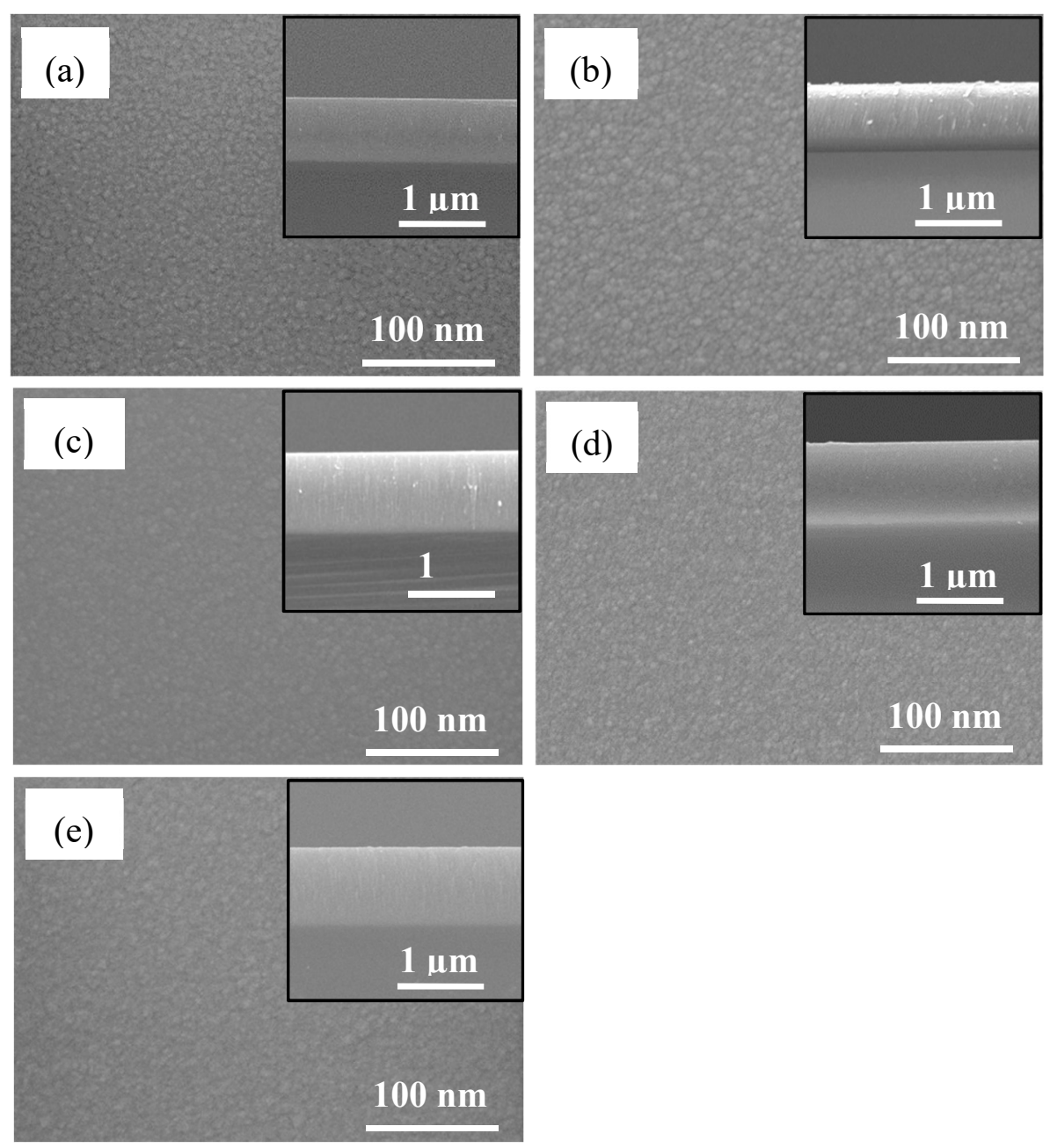

Figure 4. SEM surface morphologies of the deposited Sb- $x$-GaN thin films with $x=$ (a) 0 , (b) 0.04 , (c) 0.07 , (d) 0.14 , and (e) 0.2 . The insets are the individual cross-section images.

Table 3. Data on film growth and roughness of Sb- $x-\mathrm{GaN}$ films at $x=0,0.04,0.07,0.14$, and 0.2.

\begin{tabular}{cccc}
\hline $\boldsymbol{x}$ & $\begin{array}{c}\text { Film Thickness } \\
(\boldsymbol{\mu \mathbf { m } )}\end{array}$ & $\begin{array}{c}\text { Deposition Rate } \\
(\mathbf{n m} / \mathbf{m i n})\end{array}$ & $\begin{array}{c}\text { Roughness } \\
(\mathbf{n m})\end{array}$ \\
\hline 0 & $0.96 \pm 0.05$ & $32.00 \pm 1.60$ & $0.76 \pm 0.04$ \\
0.04 & $1.00 \pm 0.05$ & $33.33 \pm 1.67$ & $0.88 \pm 0.05$ \\
0.07 & $1.14 \pm 0.06$ & $38.00 \pm 1.90$ & $1.48 \pm 0.08$ \\
0.14 & $1.17 \pm 0.06$ & $39.00 \pm 2.00$ & $1.26 \pm 0.07$ \\
0.20 & $1.20 \pm 0.06$ & $40.00 \pm 2.00$ & $1.00 \pm 0.05$ \\
\hline
\end{tabular}

AFM images of Sb- $x$-GaN films after the 5 by $5 \mu \mathrm{m}^{2}$ dimensional scan are shown in Figure 5. The root-mean-square (rms) roughness values of $\mathrm{Sb}-x$-GaN films were $0.76 \pm 0.04,0.88 \pm 0.05,1.48 \pm 0.08$, $1.26 \pm 0.07$, and $1.0 \pm 0.05 \mathrm{~nm}$ as the antimony dopant content in Sb- $x-\mathrm{GaN}$ films increased from $x=0$, $0.04,0.07,0.14$, to 0.2 , respectively, reaching a maximum for Sb-0.07-GaN. The surface roughness of the RF-sputtered GaN film was the range of 0.7-20 nm [34], while it was 0.5-3 nm for GaN films grown by MOCVD [35]. With surface roughness value of the RF-deposited Sb- $x$-GaN films in the range from 0.76 
\pm 0.04 to $1.48 \pm 0.08 \mathrm{~nm}$, it indicated that the $\mathrm{Sb}-x-\mathrm{GaN}$ thin films were much smoother with the help of $\mathrm{Sb}$ incorporation.

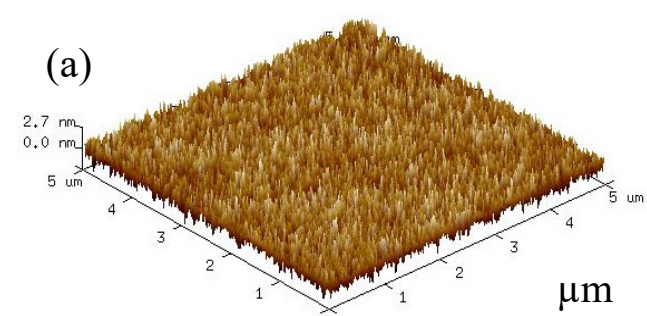

RMS: $\quad 0.76$

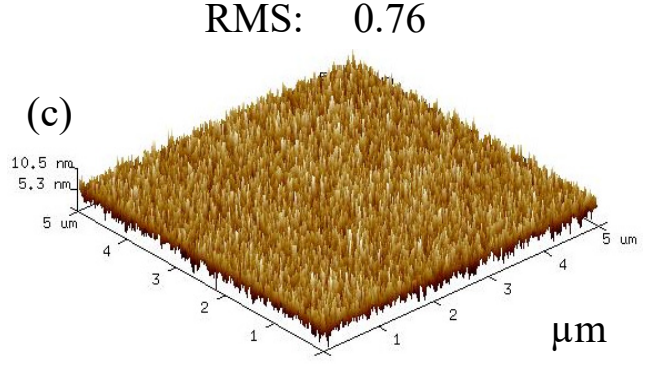

RMS: $\quad 1.48$

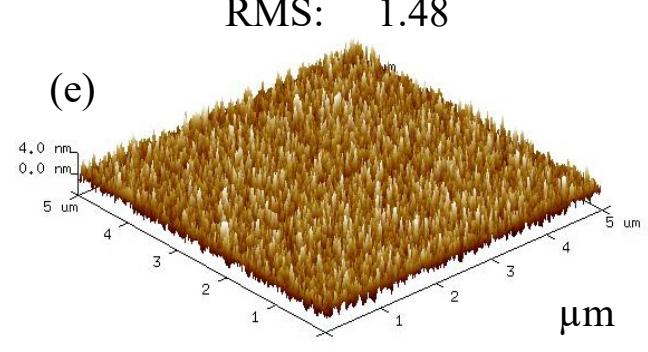

RMS: $\quad 1.0$

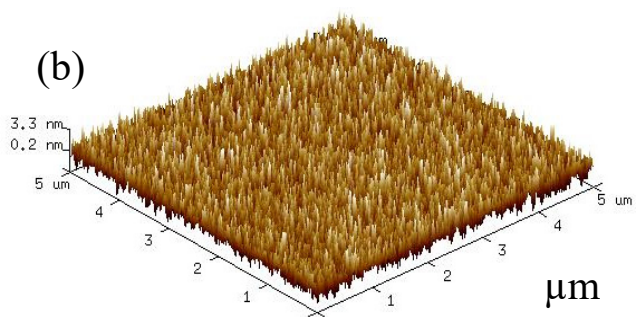

RMS: $\quad 0.88$

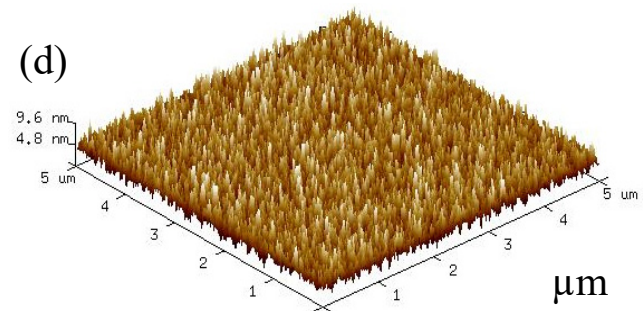

RMS: $\quad 1.26$

Figure 5. 3D atomic force microscopy (AFM) morphological images of Sb- $x$-GaN thin films at $x(\mathbf{a})=0$, (b) 0.04 , (c) 0.07 , (d) 0.14 , and (e) 0.2 .

Optical properties of grown $\mathrm{Sb}-x$-GaN films on quartz substrate were tested by UV-vis spectroscopy at $25{ }^{\circ} \mathrm{C}$. From UV-vis data, the optical absorption coefficient and energy bandgap $\mathrm{E}_{\mathrm{g}}$ of the $\mathrm{Sb}-x$-GaN films could be computed by using Tauc Equation (1) represented below.

$$
(\alpha \mathrm{h} v)^{2}=A \cdot\left(h v-\mathrm{E}_{\mathrm{g}}\right)
$$

where $\alpha$ is optical absorption coefficient of, $A$ is a constant, $h v$ is energy of the incident photon, and $E_{g}$ is the energy band-gap of the Sb- $x$-GaN thin films. Figure 6 presents the plots of the $(\alpha h v)^{2}$ $-\mathrm{h} v$ curves and extrapolation lines of the linear part of these plots. From these extrapolation lines, the energy bandgap of these films could be calculated and the $E_{\mathrm{g}}$ values of deposited $\mathrm{Sb}-x-\mathrm{GaN}$ film were 3.2, 3.04, 3.0, 2.81, and $2.72 \mathrm{eV}$ for Sb- $x$-GaN films at $x=0,0.04,0.07,0.14$, and 0.2 , respectively. From EDS composition analysis of Sb- $x$-GaN films at $x=0,0.04,0.07,0.14$, and 0.2 in the experiment, the $[\mathrm{Sb}] /([\mathrm{Sb}]+[\mathrm{Ga}])$ molar ratios were $0,1.6 \pm 0.1,2.8 \pm 0.2,9.7 \pm 0.5$, and $12.8 \pm 0.7$, respectively. The higher $\mathrm{Sb}$ content in $\mathrm{Sb}-x-\mathrm{GaN}$ target resulted the higher $[\mathrm{Sb}] /([\mathrm{Sb}]+[\mathrm{Ga}])$ ratios in $\mathrm{Sb}-x-\mathrm{GaN}$ film, while their bandgap reduced from 3.2 to $2.72 \mathrm{eV}$, presenting the solid solution of Sb into GaN to cause the defect levels and to decrease in the energy bandgap. K. M. Yu reported that $\mathrm{GaN}_{1-x} \mathrm{Sb}_{x}$ alloys had the change of edge-absorption from $3.4 \mathrm{eV}(\mathrm{GaN})$ to $1 \mathrm{eV}$ for alloys containing more than 30 at.\% $\mathrm{Sb}$ [20]. Neugebauer et al. indicated that in p-type GaN the nitrogen vacancy (a donor) has the lowest formation energy, in n-type GaN the gallium vacancy (an acceptor) [36]. Mattila et al. found clear confirmation for complicated formation between the positively charged donors and negatively charged 
cation vacancies [37]. In the Sb- $x$-GaN thin film, Sb not only behaved as an acceptor of $\mathrm{Sb}^{3-}$ in heavily doped GaN but also an isovalent dopant of $\mathrm{Sb}^{3+}$.

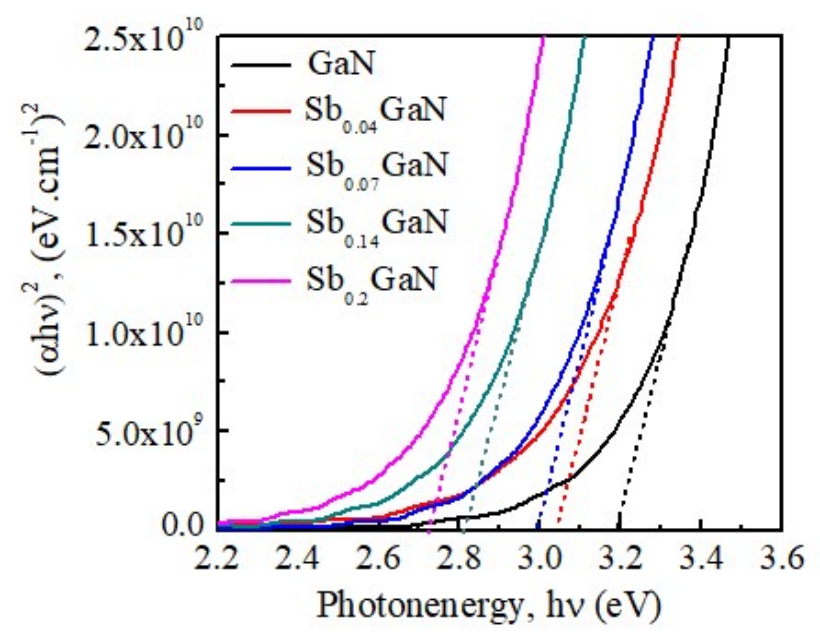

Figure 6. Plots of $(\alpha h v)^{2}$ versus photon energy (hv) for the optical bandgap denotation of the Sb-doped GaN films at different $\mathrm{Sb}$ dopants.

Hall effect measurement system was applied to investigate the electrical characteristics of Sb- $x$-GaN films at $x=0,0.04,0.07,0.14$, and 0.2 . Figure 7 shows the variation of carrier concentration, mobility, and electrical conductivity of Sb- $x-\mathrm{GaN}$ films $(x=0,0.04,0.07,0.14$, and 0.2$)$. The Hall effect measurement system was used to measure the carrier concentration and electrical mobility of $\mathrm{Sb}-\mathrm{x}-\mathrm{GaN}$ films. In this test, to prevent the measured current being affected from the $n$-Si substrate, the first step to do before $\mathrm{SbGaN}$ deposition is to have a $\mathrm{SiO}_{2}$ layer with $300 \mathrm{~nm}$ of thickness deposited on the $\mathrm{n}-\mathrm{Si}$ substrate by DC magnetron sputtering, and then $\mathrm{Sb}-\mathrm{x}-\mathrm{GaN}$ film was deposited on $\mathrm{SiO}_{2} / \mathrm{n}-\mathrm{Si}$ substrate. Silver electrodes was deposited at the four corners to form a conductive electrode before measurement. The Hall effect measurement system uses the Lorentz force in the magnetic field to shift the direction of charge carriers. The difference in voltage caused by the accumulation of electrons or holes is to determine Sb- $x$-GaN n-type or p-type. In this work, Sb-0-GaN and Sb-0.04-GaN films remained as a $n$-type semiconductor. $\mathrm{Sb}-0-\mathrm{GaN}$ film had average electron concentration $\left(\mathrm{N}_{\mathrm{e}}\right)$ of $(1.4 \pm 0.1) \times 10^{17} \mathrm{~cm}^{-3}$ and mobility of $(3.0 \pm 0.2) \mathrm{cm}^{2} \cdot \mathrm{V}^{-1} \cdot \mathrm{s}^{-1}(\mu)$, while Sb-0.04-GaN film had the reduced $\mathrm{N}_{\mathrm{e}}$ of $(4.9 \pm 0.3) \times$ $10^{15} \mathrm{~cm}^{-3}$ and an increase of electron mobility $(\mu)$ of $(17.0 \pm 0.9) \mathrm{cm}^{2} \cdot \mathrm{V}^{-1} \cdot \mathrm{s}^{-1}$. It is important to note that $\mathrm{Sb}-0.07-\mathrm{GaN}$ underwent the n-to-p transition stage. The Sb-0.07-GaN, Sb-0.14-GaN, and Sb-0.2-GaN films had an increase in positively charged carriers concentration from $(5.2 \pm 0.3) \times 10^{15},(2.9 \pm 0.2)$ $\times 10^{16}$, to $(5.5 \pm 0.3) \times 10^{17} \mathrm{~cm}^{-3}$, respectively, while their electrical mobilities were $74 \pm 4,287 \pm 15$, and $165 \pm 9 \mathrm{~cm}^{2} \cdot \mathrm{V}^{-1} \cdot \mathrm{s}^{-1}$, respectively. It could be believed that $\mathrm{Sb}-0.07-\mathrm{GaN}$ film experienced at the n-to-p transition stage and remained lower hole concentration of $(5.2 \pm 0.3) \times 10^{15} \mathrm{~cm}^{-3}$. With a higher $\mathrm{Sb}$ content in target, Sb-0.14-GaN film contained higher hole concentration of $(2.9 \pm 0.2) \times 10^{16} \mathrm{~cm}^{-3}$ and electrical mobility of $(287 \pm 15) \mathrm{cm}^{2} . \mathrm{V}^{-1} \cdot \mathrm{s}^{-1}$. Sb-0.2-GaN film had the highest hole concentration of $(5.5 \pm 0.3) \times 10^{17} \mathrm{~cm}^{-3}$, and hole mobility of $(165 \pm 9) \mathrm{cm}^{2} \cdot \mathrm{V}^{-1} \cdot \mathrm{s}^{-1}$. The highest hole concentration for $\mathrm{Sb}-0.2-\mathrm{GaN}$ explained its lower mobility due to the increased hole concentration. After calculating the carrier concentration and electrical mobility, the electrical conductivity values are determined as $(0.07 \pm 0.01),(0.02 \pm 0.01),(0.06 \pm 0.01),(1.30 \pm 0.07)$, and $(14.5 \pm 0.8) \mathrm{S} \cdot \mathrm{cm}^{-1}$ for Sb- $x-\mathrm{GaN}$ films at $x=0$, $0.04,0.07,0.14$, and 0.2 , respectively. Electrical properties of Sb- $x-\mathrm{GaN}$ films could be improved by the incorporation of Sb into GaN lattice. From EDS data in Table 1, the $[\mathrm{Sb}] /([\mathrm{Sb}]+[\mathrm{Ga}])$ molar ratios in the sputtered film were $0,1.6 \pm 0.1,2.8 \pm 0.2,9.7 \pm 0.5$, and $12.8 \pm 0.7$, Sb contents added in SbGaN targets were $0,4,7,14$, and 20 at.\%, respectively. There was an increase in the Sb dopant concentration in the films when the higher Sb content was in target. The increased Sb content in films led to the conversion of the $n-\mathrm{GaN}$ into $p$-GaN. Here is the explanation for the $n$-to- $p$ conversion with the Sb substitution in 
GaN. The film composition is always the major factor in controlling its physical properties. The GaN film was anion deficient at the lower $\mathrm{Sb}$ content and cation deficient at the higher $\mathrm{Sb}$ content, as shown in Table 1. It is the nitrogen vacancy to contribute the $n$-type behavior and the gallium vacancy to the p-type behavior.

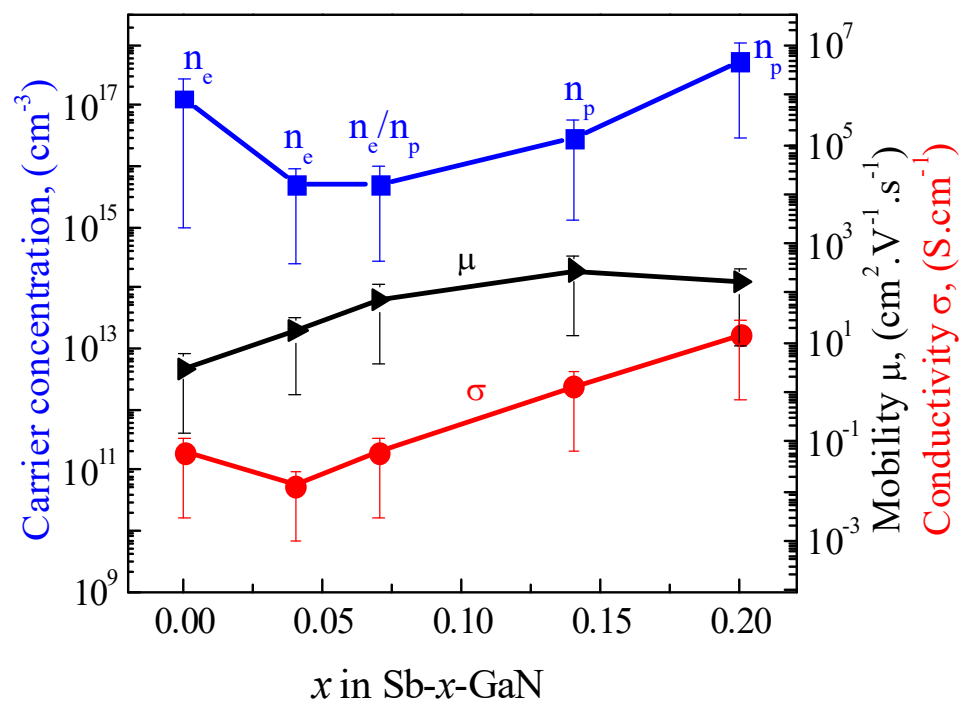

Figure 7. Electrical characteristics of carrier concentration $\left(n_{e}, n_{p}\right)$, mobility $(\mu)$, and conductivity $(\sigma)$ (with the standard deviation at $5 \%$ ) of $\mathrm{Sb}-x$-GaN films grown at RF power of $120 \mathrm{~W}$ and heating temperature of $300{ }^{\circ} \mathrm{C}$ with different dopant $\mathrm{Sb}$ contents.

The $p$-type conduction behavior is enhanced at the higher $\mathrm{Sb}$ content in film with a lower cation/anion value less than 1.0 or more Ga vacancies, as shown in Figure 7. With increasing the $\mathrm{Sb}$ content at the $\mathrm{N}$ site, the $\mathrm{Sb}-\mathrm{GaN}$ crystal is supposed to have a huge expansion in unit cell. However, the expansion of unit cell by $\mathrm{Sb}$ substitution is limited due to the offset caused by the formation of $\mathrm{Ga}$ vacancy at the higher $\mathrm{Sb}$ content, as shown in Table 2. With the big $\mathrm{Sb}$ anion on the $\mathrm{N}$ site and the formed Ga vacancies at a higher $\mathrm{Sb}$ content in the $(\mathrm{Ga}, \mathrm{Sb})(\mathrm{Sb}, \mathrm{N})$ film, the lattice distortion becomes severe due to the complex lattice defects. Therefore, $\mathrm{Sb}-0.2-\mathrm{GaN}$ film has shown the smaller crystallite size and worse crystallinity, as shown in Figure 3. Basically, both of GaSb and GaN are $n$-type semiconductors with band gaps of 0.726 and $3.4 \mathrm{eV}$ and electron mobilities of 3000 and $1500 \mathrm{~cm}^{2} . \mathrm{V}^{-1} \cdot \mathrm{s}^{-1}$, respectively. Their mixture to form the alloy is expected to form lower bandgap, as shown in Figure 6 for our data from $3.2 \mathrm{eV}$ to $2.72 \mathrm{eV}$. However, in this work $\mathrm{Sb}$ in $\mathrm{Sb}-x-\mathrm{GaN}$ at a higher content of $x=0.2$ prefers to substitute the Ga cation site. The $n$-to- $p$ conversion by incorporating $\mathrm{Sb}$ is special. Limited data were reported for the group $\mathrm{V}$ anion instead of cation doping on $\mathrm{GaN}$ [18-22]. Our work can have its contribution on the HMA field for further development.

To further confirm Sb- $x$-GaN films (at $x=0.07,0.14$, and 0.2) acting as $p$-type semiconductor, three hetero-junction diodes were prepared by Sb-0.07-GaN, Sb-0.14-GaN, and Sb-0.2-GaN films sputtered on $n$-Si substrates, respectively. The electrical characteristics of $p-\mathrm{SbGaN} / n-\mathrm{Si}$ hetero junction diodes were investigated by Semiconductor Device Analyzer (Agilent, B1500A) at the room temperature. Figures 8 and 9 show the forward and reverse current density-voltage $J-V$ and $\log (J)-V$ characteristics, respectively, of $p$-SbGaN $/ n$-Si diodes investigated from -20 to $+20 \mathrm{~V}$ at $25^{\circ} \mathrm{C}$. The data from the $J-V$ curves display that the turn-on voltages are determined to be $1.5,1.25$, and $1.0 \mathrm{~V}$ for Sb-0.07-GaN, $\mathrm{Sb}-0.14-\mathrm{GaN}$, and Sb-0.2-GaN diode devices, respectively, while the breakdown voltages were above $20 \mathrm{~V}$. At the $20 \mathrm{~V}$ forward bias, the Sb-0.2-GaN device had the highest current density of $0.253 \mathrm{~A} / \mathrm{cm}^{2}$, while they were 0.033 and $0.139 \mathrm{~A} / \mathrm{cm}^{2}$ for Sb-0.07-GaN and Sb-0.14-GaN devices. The parameters and the electrical properties of $p$-SbGaN/n-Si devices are listed in Table 4 . The leakage current density at $-5 \mathrm{~V}$ was $2.70 \times 10^{-5}, 5.13 \times 10^{-5}$, and $9.41 \times 10^{-5} \mathrm{~A} / \mathrm{cm}^{2}$ for $p$-Sb- $x$-GaN films at $x=0.07,0.14$, and 0.20 , respectively. It can be explained that the electrical properties of $p-\mathrm{Sb}-0.07-\mathrm{GaN}, p-\mathrm{Sb}-0.14-\mathrm{GaN}$, 
and $p$-Sb-0.2-GaN films shown in Figure 6 are related to the differences of leakage current density and forward current density of the diodes displayed in Figures 8 and 9. The higher values of the leakage current density and the forward current density of $p-\mathrm{Sb}-x-\mathrm{GaN} / n-\mathrm{Si}$ devices can result from the higher electrical conductivity for $p$-Sb- $x$-GaN films.

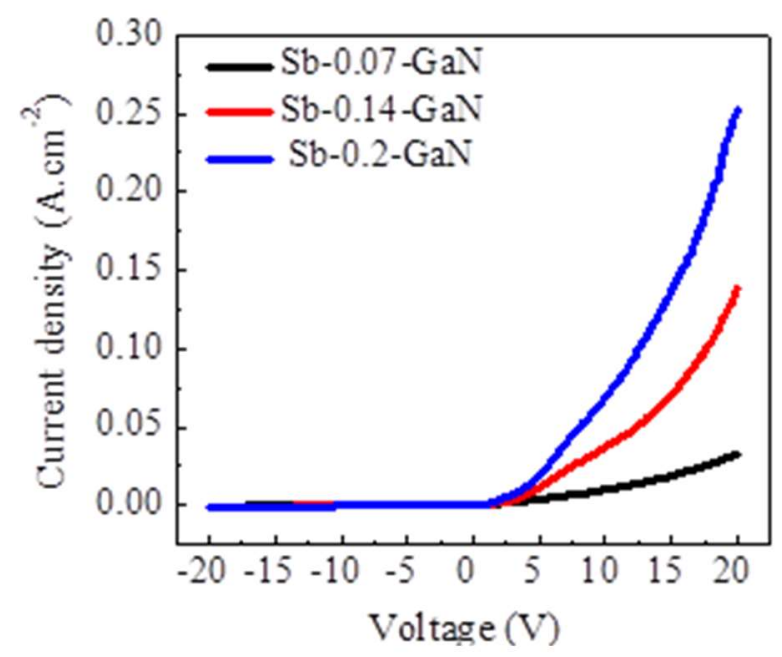

Figure 8. Electrical properties of hetero junction p-Sb-x-GaN/n-Si diodes measured at room temperature.

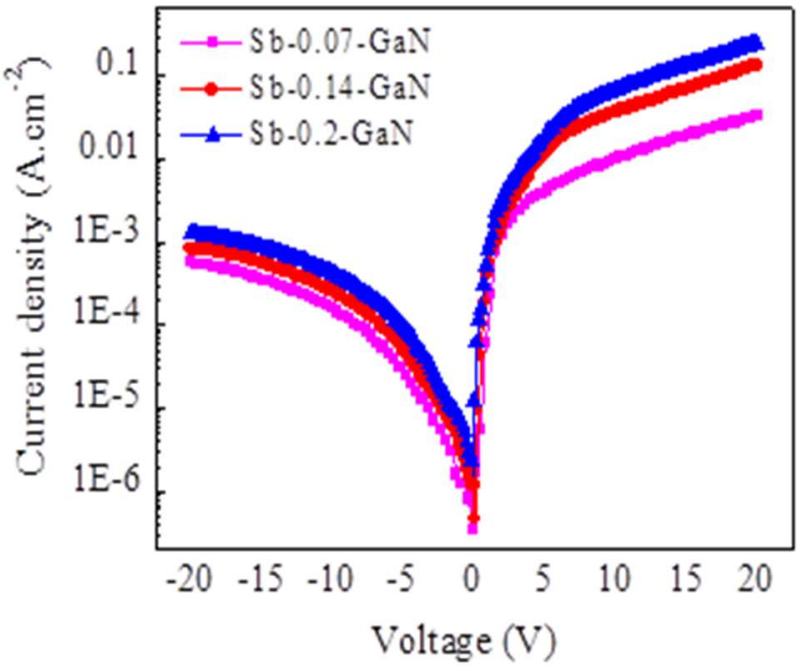

Figure 9. The reverse and forward current density-voltage $\log (J)-V$ plots of $p-\mathrm{Sb}-x-\mathrm{GaN} / n$-Si diodes (at $x=0.07,0.14$, and 0.2 ) tested at room temperature.

Table 4. Electrical characteristics of $p-\mathrm{SbGaN} / n$-Si diodes.

\begin{tabular}{cccccc}
\hline \multirow{2}{*}{ Diodes } & \multirow{2}{*}{$\begin{array}{c}\text { Leakage Current } \\
\text { Density }\left(\mathbf{A} / \mathbf{c m}^{\mathbf{2}}\right) \text { at } \mathbf{- 5} \mathbf{~ V}\end{array}$} & $\begin{array}{c}\text { Barrier Height } \\
\boldsymbol{\phi}_{\boldsymbol{B}}(\mathbf{e V})\end{array}$ & \multicolumn{1}{c}{$\boldsymbol{I - V}$} & \multicolumn{2}{c}{ Cheung's dV/dlnI Versus I } \\
\cline { 4 - 6 } & & & $\mathbf{n}$ & $\mathbf{R s} \mathbf{( k \boldsymbol { }})$ & $\mathbf{n}$ \\
\hline $\mathrm{Sb}-0.07-\mathrm{GaN}$ & $2.70 \times 10^{-5}$ & 0.49 & 5.95 & 8.34 & 5.44 \\
$\mathrm{Sb}-0.14-\mathrm{GaN}$ & $5.13 \times 10^{-5}$ & 0.45 & 6.12 & 7.51 & 5.59 \\
$\mathrm{Sb}-0.2-\mathrm{GaN}$ & $9.41 \times 10^{-5}$ & 0.44 & 6.54 & 3.91 & 5.95 \\
\hline
\end{tabular}

Using a standard thermionic-emission (TE) model as the mathematic statement, the electrical characteristics of the diode can be computed (for $\mathrm{qV}>3 \mathrm{kT}$ ). The equation is as shown below $[28,29,38,39]$ :

$$
I=I_{0}\left[\exp \frac{q}{n k T}\left(V-I R_{s}\right)\right]
$$


where $q$ is the electron charge $\left(1.60 \times 10^{-19} \mathrm{C}\right), I_{0}$ the saturation current, $V$ the supplied voltage, $n$ is the ideality factor, $R_{S}$ is the series resistance, $K$ is Boltzmann constant $\left(1.38 \times 10^{-23} \mathrm{~J} \cdot \mathrm{K}^{-1}\right)$, and T is the experiment temperature in Kelvin. With the curve of $\ln \mathrm{I}$ versus $\mathrm{V}$ drawn by applying Equation (2), the saturation current $I_{0}$ can be retrieved by intersecting the interpolated straight line from the linear region of the semilog plot. The $I_{0}$ values were $1.38 \times 10^{-5}, 7.60 \times 10^{-5}$ and $1.17 \times 10^{-4} \mathrm{~A}$ for $p$-Sb- $x$-GaN diodes at $x=0.07,0.14$, and 0.2 . With the help of the retrieved $I_{0}$ data, the barrier height can be found by using Equation (3) [28,38,39].

$$
\phi_{B}=\frac{K T}{q} \ln \left[\frac{A A^{*} T^{2}}{I_{0}}\right]
$$

where $\mathrm{A}$ is the area of the diode with the dimension of $1 \times 1 \mathrm{~mm}^{2}, A^{*}$ the effective Richardson constant $K$ is Boltzmann constant $\left(1.38 \times 10^{-23} \mathrm{~J} \cdot \mathrm{K}^{-1}\right)$, and T is the experiment temperature in Kelvin, and $\varnothing_{B}$ he barrier height. In this formula, for $p$-GaN diodes, the value of $A^{*}$ in theory was computed to be $26.4 \mathrm{~A} \cdot \mathrm{cm}^{-2} \cdot \mathrm{K}^{-2}$ with $m^{*}=0.22 \mathrm{~m}_{\mathrm{e}}$, while the $A^{*}$ was calculated to be $23 \mathrm{~A} \cdot \mathrm{cm}^{-2} \cdot \mathrm{K}^{-2}$ with $m^{*}=0.19 \mathrm{~m}$ for $n$-InGaN diodes $[25,38]$. The ideality factor $\mathrm{n}$ can be determined by the slope of the linear region in forward bias $[38,40,41]$. It can be counted from the following equation:

$$
n=\left(\frac{q}{K T}\right)\left(\frac{d V}{d(\ln I)}\right)
$$

From Equation (4) and Figure 10 for the $\mathrm{dV} / \mathrm{d}(\operatorname{lnI})$ versus current curves, the ideality factor $n$ can be computed to be $5.95,6.12$, and 6.54 , and the barrier height $\phi_{B}$ to be $0.49,0.45$, and $0.44 \mathrm{eV}$ for Sb- $x$-GaN diodes at $x=0.07,0.14$, and 0.2 , respectively. Table 4 displays the electrical characteristics of $\mathrm{Sb}-x$-GaN diodes at $x=0.07,0.14$, and 0.2. It is shown that the decrease of turn-on voltage is corelated with the lower barrier height.

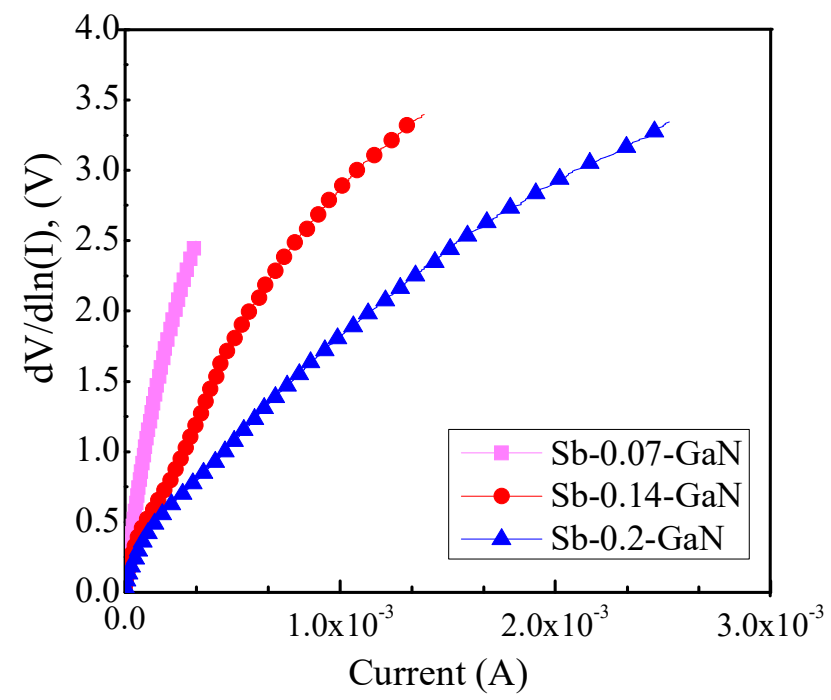

Figure 10. Plots of $\mathrm{dV} / \mathrm{d} \ln (\mathrm{I})$ versus current density for $p-\mathrm{Sb}-x-\mathrm{GaN} / n-\mathrm{Si}$ junction diodes with $x=0.07$, 0.14 , and 0.2 .

Cheung's equation is presented by the below equation and contains the series resistance $R_{S}$ and ideality factor $n$ [38-42].

$$
\left(\frac{d V}{d(\ln I)}\right)=\frac{n K T}{q}+I R_{s}
$$

By using Equation (5), the $R_{S}$ series resistance and $\mathrm{n}$ ideality factor for the hetero-junction diodes were calculated and shown in Table 4 . The ideality factor $\mathrm{n}$ was $5.44,5.59$, and 5.94 and the series resistance $R_{S}$ was $8.34,7.51$, and $3.91 \mathrm{k} \Omega$ for Sb- $x$-GaN diodes at $x=0.07,0.14$, and 0.2 , respectively. 
For Schottky diode, the ideality factor is often $<2$. The ideality factors of our hetero junction diodes had higher values because of the high series resistances, which had been studied by the Cheungs' method. The high $R_{S}$ series resistance also affects the current transport mechanism of the hetero junction diode. In addition to the reasons such as accelerated recombination of electrons and holes in depletion region, the occurrence of lattice distortion and the presence of crystalline and amorphous regions could also lead to the higher ideality factor in hetero junction diode $[23,25,29]$.

\section{Conclusions}

$\mathrm{Sb}$ acceptor-doped GaN thin films were successfully grown on $\mathrm{Si}(100)$ substrates by radio frequency reactive sputtering with antimony-containing cermet targets. The grown $\mathrm{Sb}-x-\mathrm{GaN}$ films had a smooth surface and crystallized into the wurtzite structure with a preferential (1010) growth plane. The energy bandgap for Sb- $x$-GaN films was in the range of $2.72-3.2 \mathrm{eV}$. The Sb- $x$-GaN films transformed into $p$-type semiconductors at $x=0.07,0.14$, and 0.2 , with the Sb-0.2-GaN film having high hole conductivity of $(14.5 \pm 0.8){\mathrm{S} . \mathrm{cm}^{-1}}^{-1}$, high hole concentration of $(5.5 \pm 0.3) \times 10^{17} \mathrm{~cm}^{-3}$, and high electrical mobility of $(165 \pm 9) \mathrm{cm}^{2} \cdot \mathrm{V}^{-1} \cdot \mathrm{S}^{-1}$. The electrical characteristics of $p-\mathrm{Sb}-x-\mathrm{GaN} / n-\mathrm{Si}$ diodes with $x=0.07,0.14$, and 0.2 were intensively tested at $25^{\circ} \mathrm{C}$ in range from -20 to $20 \mathrm{~V}$. The devices with the increased $\mathrm{Sb}$ contents experienced an increase of the leakage current densities from $2.7 \times 10^{-5}$ to $9.41 \times 10^{-5} \mathrm{~A} / \mathrm{cm}^{2}$ at $-5 \mathrm{~V}$, the decreased barrier height from 0.49 to $0.44 \mathrm{eV}$, and the increased forward current density from 0.033 to $0.139 \mathrm{~A} \cdot \mathrm{cm}^{-2}$. The coexistence of acceptor defects of Ga vacancy for the p-type conduction and the highly mismatched $\mathrm{Sb}$ at cation and anion sites in $\mathrm{Sb}-\mathrm{GaN}$ films at a higher $\mathrm{Sb}$ content can be important in developing the highly mismatched alloys.

Author Contributions: Data curation, T.T.A.T., and C.P.T.; Formal analysis, T.T.A.T., C.P.T., and W.-C.K.; Funding acquisition, T.T.A.T., C.P.T., and T.T.V.S.N.; Investigation, T.T.A.T., C.P.T.; Methodology, T.T.A.T., C.P.T., and W.-C.K.; Supervision, D.-H.K.; Writing-review \& editing, C.P.T., W.-C.K., and T.T.V.S.N. All authors have read and agreed to the published version of the manuscript.

Funding: This research was funded by the Ministry of Science and Technology of the Republic of China under grant number 107-2221-E-011-141-MY3.

Acknowledgments: In this section you can acknowledge any support given which is not covered by the author contribution or funding sections. This may include administrative and technical support, or donations in kind (e.g., materials used for experiments).

Conflicts of Interest: The authors declare no conflict of interest.

\section{References}

1. Jain, S.C.; Willander, M.; Narayan, J.; Overstraeten, R.V. III-nitrides-Growth, characterization, and properties. J. Appl. Phys. 2000, 87, 965-1006. [CrossRef]

2. Fujii, T.; Gao, Y.; Sharma, R.; Hu, E.L.; DenBaars, S.P.; Nakamura, S. Increase in the extraction efficiency of GaN-based light-emitting diodes via surface roughening. Appl. Phys. Lett. 2004, 84, 855-857. [CrossRef]

3. Shuji, N.; Takashi, M.; Masayuki, S. High-Power GaN P-N junction blue-light-emitting diodes. Jpn. J. Appl. Phys. 1991, 30, L1998.

4. Rajan, S.; Chini, A.; Wong, M.H.; Speck, J.S.; Mishra, U.K. N-polar GaN/AlGaN/GaN high electron mobility transistors. J. Appl. Phys. 2007, 102, 044501. [CrossRef]

5. Pearton, S.J.; Ren, F.; Zhang, A.P.; Lee, K.P. Fabrication and performance of GaN electronic devices. Mater. Sci. Eng. R. Rep. 2000, 30, 195-212. [CrossRef]

6. Shuji, N. GaN growth using gan buffer layer. Jpn. J. Appl. Phys. 1991, 30, L1705.

7. Shota, K.; Kazumasa, H.; Nobuhiko, S. Fabrication of GaN hexagonal pyramids on dot-patterned GaN/Sapphire substrates via selective metalorganic Vapor Phase Epitaxy. Jpn. J. Appl. Phys. 1995, 34, L1184.

8. Akasaki, I.; Amano, H.; Koide, Y.; Hiramatsu, K.; Sawaki, N. Effects of ain buffer layer on crystallographic structure and on electrical and optical properties of $\mathrm{GaN}$ and $\mathrm{Ga}_{1-\mathrm{x}} \mathrm{Al}_{\mathrm{x}} \mathrm{N}(0<\mathrm{x}<0.4)$ films grown on sapphire substrate by MOVPE. J. Cryst. Growth 1989, 98, 209-219. 
9. Hiroshi, A.; Masahiro, K.; Kazumasa, H.; Isamu, A. P-type conduction in Mg-Doped GaN treated with Low-Energy Electron Beam Irradiation (LEEBI). Jpn. J. Appl. Phys. 1989, 28, L2112.

10. Nakamura, S.; Harada, Y.; Seno, M. Novel metalorganic chemical vapor deposition system for GaN growth. Appl. Phys. Lett. 1991, 58, 2021-2023. [CrossRef]

11. Shuji, N.; Takashi, M.; Masayuki, S.; Naruhito, I. Thermal annealing effects on P-Type Mg-Doped GaN films. Jpn. J. Appl. Phys. 1992, 31, L139.

12. Van de Walle, C.G.; Stampfl, C.; Neugebauer, J. Theory of doping and defects in III-V nitrides. J. Cryst. Growth 1998, 189, 505-510. [CrossRef]

13. Guarneros, C.; Sánchez, V. Magnesium doped GaN grown by MOCVD. Mater. Sci. Eng. B 2010, 174, $263-265$. [CrossRef]

14. Fischer, S.; Wetzel, C.; Haller, E.E.; Meyer, B.K. On p-type doping in GaN-acceptor binding energies. Appl. Phys. Lett. 1995, 67, 1298-1300. [CrossRef]

15. Amano, H.; Hiramatsu, K.; Kito, M.; Sawaki, N.; Akasaki, I. Zn related electroluminescent properties in MOVPE grown GaN. J. Cryst. Growth 1988, 93, 79-82. [CrossRef]

16. Li, C.C.; Kuo, D.H. Material and technology developments of the totally sputtering-made p/n GaN diodes for cost-effective power electronics. Mater. Sci. Mater. Electron. 2014, 25, 1942-1948. [CrossRef]

17. Segercrantz, N.; Yu, K.M.; Ting, M.; Sarney, W.L.; Svensson, S.P.; Novikov, S.V.; Foxon, C.T.; Walukiewicz, W. Electronic band structure of highly mismatched $\mathrm{GaN}_{1-x} \mathrm{Sb}_{x}$ alloys in a broad composition range. Appl. Phys. Lett. 2015, 107, 142104. [CrossRef]

18. Segercrantz, N.; Baumgartner, Y.; Ting, M.; Yu, K.M.; Mao, S.S.; Sarney, W.L.; Svensson, S.P.; Walukiewicz, W. Undoped p-type $\mathrm{GaN}_{1-\mathrm{x}} \mathrm{Sb}_{\mathrm{x}}$ alloys: Effects of annealing. Appl. Phys. Lett. 2016, 109, 252102. [CrossRef]

19. Yu, K.; Novikov, S.; Ting, M.; Sarney, W.; Svensson, S.; Shaw, M.; Martin, R.; Walukiewicz, W.; Foxon, C. Growth and characterization of highly mismatched $\mathrm{GaN}_{1-\mathrm{x}} \mathrm{Sb}_{\mathrm{x}}$ alloys. J. Appl. Phys. 2014, 116, 123704. [CrossRef]

20. Yu, K.M.; Sarney, W.L.; Novikov, S.V.; Detert, D.; Zhao, R.; Denlinger, J.D.; Svensson, S.P.; Dubon, O.D.; Walukiewicz, W.; Foxon, C.T. Highly mismatched N-rich $\mathrm{GaN}_{1-\mathrm{x}} \mathrm{Sb}_{\mathrm{x}}$ films grown by low temperature molecular beam epitaxy. Appl. Phys. Lett. 2013, 102, 102104. [CrossRef]

21. Segercrantz, N.; Makkonen, I.; Slotte, J.; Kujala, J.; Veal, T.D.; Ashwin, M.J.; Tuomisto, F. Increased p-type conductivity in $\mathrm{GaN}_{\mathrm{x}} \mathrm{Sb}_{1-\mathrm{x}}$, experimental and theoretical aspects. J. Appl. Phys. 2015, 118, 085708. [CrossRef]

22. Yu, K.M.; Sarney, W.L.; Novikov, S.V.; Segercrantz, N.; Ting, M.; Shaw, M.; Svensson, S.P.; Martin, R.W.; Walukiewicz, W.; Foxon, C.T. Highly mismatched $\mathrm{GaN}_{1-\mathrm{x}} \mathrm{Sb}_{\mathrm{x}}$ alloys: Synthesis, structure and electronic properties. Semicond. Sci. Technol. 2016, 31, 083001. [CrossRef]

23. Tuan, T.T.A.; Kuo, D.H.; Lin, K.; Li, G.Z. Temperature dependence of electrical characteristics of $\mathrm{n}-\mathrm{In} x \mathrm{Ga} 1-\mathrm{xN} / \mathrm{p}-\mathrm{Si}$ hetero-junctions made totally by RF magnetron sputtering. Thin Solid Films 2015, 589, 182-187. [CrossRef]

24. Kuo, D.H.; Li, C.C.; Tuan, T.T.A.; Yen, C.L. Effects of Mg doping on the performance of InGaN films made by reactive sputtering. J. Electron. Mater. 2014, 44, 210-216. [CrossRef]

25. Tuan, T.T.A.; Kuo, D.H.; Albert, D.S.; Li, G.Z. Electrical properties of RF-sputtered Zn-doped GaN films and $\mathrm{p}-\mathrm{Zn}-\mathrm{GaN} / \mathrm{n}$-Si hetero junction diode with low leakage current of $10^{-9} \mathrm{~A}$ and a high rectification ratio above 105. Mater. Sci. Eng. B 2017, 222, 18-25. [CrossRef]

26. Thao, C.P.; Kuo, D.H. Electrical and structural characteristics of Ge-doped GaN thin films and its hetero-junction diode made all by RF reactive sputtering. Mater. Sci. Semicond. Process 2018, 74, 336-341. [CrossRef]

27. Li, C.C.; Kuo, D.H. Effects of growth temperature on electrical and structural properties of sputtered GaN films with a cermet target. J. Matter Sci. Mater. Electron. 2014, 25, 1404-1409. [CrossRef]

28. Tuan, T.T.A.; Kuo, D.H.; Thao, C.P.; Pham, Q.P.; Nghi, V.K.; Tran, N.P.L. Electrical and Structural Properties of All-Sputtered Al/SiO ${ }_{2} / \mathrm{p}-\mathrm{GaN}$ MOS Schottky Diode. Coatings 2019, 9, 685.

29. Tuan, T.T.A.; Kuo, D.H.; Thao, C.P.; Nguyen, V.S.; Pham, Q.P.; Nghi, V.K.; Tran, N.P.L. Electrical characterization of RF reactive sputtered $\mathrm{p}-\mathrm{Mg}-\mathrm{InxGa1-xN/n-Si} \mathrm{hetero-junction} \mathrm{diodes} \mathrm{without} \mathrm{using}$ buffer layer. Coatings 2019, 9, 699. [CrossRef]

30. Garg, M.; Naik, T.R.; Pathak, C.S.; Nagarajan, S.; Rao, V.R.; Singh, R. Significant improvement in the electrical characteristics of Schottky barrier diodes on molecularly modified Gallium Nitride surfaces. Appl. Phys. Lett. 2018, 112, 163502. [CrossRef] 
31. Sun, Q.; Li, W.-J.; Fu, Z.-W. A novel anode material of antimony nitride for rechargeable lithium batteries. Solid State Sci. 2010, 12, 397-403. [CrossRef]

32. Ghosh, D.; Ghosh, B.; Hussain, S.; Bhar, R.; Pal, A.K. Polycrystalline GaSb films prepared by the coevaporation technique. Appl. Phys. A 2014, 115, 1251-1261. [CrossRef]

33. Seo, D.; Na, J.; Lee, S.; Lim, S. Behavior of GaSb (100) and InSb (100) surfaces in the presence of $\mathrm{H}_{2} \mathrm{O}_{2}$ in acidic and basic cleaning solutions. Appl. Surf. Sci. 2017, 399, 523-534. [CrossRef]

34. Kim, H.W.; Kim, N.H. Preparation of GaN films on ZnO buffer layers by RF magnetron sputtering. Appl. Surf. Sci. 2004, 236, 192-197. [CrossRef]

35. Chyr, I.; Lee, B.; Chao, L.C.; Steckl, A.J. Damage generation and removal in the $\mathrm{Ga}^{+}$focused ion beam micromachining of GaN for photonic applications. J. Vac. Sci. Technol. B 1999, 17, 3063-3067. [CrossRef]

36. Neugebauer, J.; Van de Walle, C.G. Atomic geometry and electronic structure of native defects in GaN. Phys. Rev. B 1994, 50, 8067-8070. [CrossRef]

37. Mattila, T.; Nieminen, R.M. Point-defect complexes and broadband luminescence in GaN and AlN. Phys. Rev. B 1997, 55, 9571-9576. [CrossRef]

38. Tuan, T.T.A.; Kuo, D.H.; Li, C.C.; Yen, W.L. Schottky barrier characteristics of Pt contacts to all sputtering-made n-type GaN and MOS diodes. Mater. Sci. Mater. Electron. 2014, 25, 3264-3270. [CrossRef]

39. Reddy, V.R.; Prasanna, B.P.; Padma, R. Electrical properties of rapidly annealed Ir and Ir/Au schottky contacts on n-Type InGaN. J. Metall. 2012, 1, 1-9. [CrossRef]

40. Tuan, T.T.A.; Kuo, D.H. Characteristics of RF reactive sputter-deposited $\mathrm{Pt} / \mathrm{SiO}_{2} / \mathrm{n}-\mathrm{InGaN}$ MOS Schottky diodes. Mater. Sci. Semicond. Process. 2015, 30, 314-320. [CrossRef]

41. Bengi, S.; Bülbül, M.M. Electrical and dielectric properties of $\mathrm{Al} / \mathrm{HfO}_{2} / \mathrm{p}-\mathrm{Si} \mathrm{MOS}$ device at high temperatures. Curr. Appl. Phys. 2013, 13, 1819-1825.

42. Cheung, S.K.; Cheung, N.W. Extraction of Schottky diode parameters from forward current-voltage characteristics. Appl. Phys. Lett. 1986, 49, 85-87. [CrossRef]

(C) 2020 by the authors. Licensee MDPI, Basel, Switzerland. This article is an open access article distributed under the terms and conditions of the Creative Commons Attribution (CC BY) license (http://creativecommons.org/licenses/by/4.0/). 